\title{
A New Type of a Magnetic Plane Motor Coupled Mechanical Vibration with Electromagnetic Force
}

\author{
Hiroyuki Yaguchi, Kazuya Iino, Takaaki Eguchi \\ Faculty of Engineering, Tohoku Gakuin University, Tagajo, Japan \\ Email: yaguchi@mail.tohoku-gakuin.ac.jp
}

Received 27 May 2014; revised 28 June 2014; accepted 10 July 2014

Copyright (C) 2014 by authors and Scientific Research Publishing Inc.

This work is licensed under the Creative Commons Attribution International License (CC BY).

http://creativecommons.org/licenses/by/4.0/

\section{(c) (i) Open Access}

\begin{abstract}
This paper proposes a new magnetic plane motor capable of rotation by the resonance energy of double-cantilever beam model excited by an electromagnetic force. This magnetic plane motor has two double-cantilever models, and the rotational direction is able to change by changing of the vibration mode. Basic characteristics of a prototype for the magnetic plane motor, such as rotational speed, output torque and efficiency were determined experimentally. Experimental results demonstrated that the rotational speed of $8.1 \mathrm{rpm}$ was obtained with output torque of $0.07 \mathrm{Ncm}$ for the magnetic plane motor having double-cantilever model. The output torque characteristics of the magnetic plane motor with two double-cantilever models improved 200 percent compared with double-cantilever model.
\end{abstract}

\section{Keywords}

Magnetic Plane Motor, Inertia Force, High Torque, Resonance-Drive, Vibration Mode

\section{Introduction}

There is an increasing demand for a micro-motor able to rotate with high promotion torque for personal computer and OA devices. Generally, an output torque in a conventional electromagnetic motor is proportional to the volume of the motor size. Therefore, the output torque decreases by the downsizing of the motor. In particular, it is very difficult to get enough torque in practical use at the dimensions of small size. A number of studies have investigated the mechanisms of the motor using devices such as an electrostatic elements [1]-[5], an electrorheological fluid [6], a shape memory alloy [7] [8], a magnetostrictive element [9]-[11], and a new type [12] by combination of a frictional force and an electromagnetic force. 
On the other hand, as the motor producing high torque at low speed, an ultrasonic motor exists. In the present, the design and the production technique are established. In addition, the ultrasonic motor is used for an electric appliance and a robot widely because the control characteristics are superior. However, this motor is very expensive although a cycle of the use is short.

In this study, we propose a new type of a magnetic plane motor which combined an electromagnetic force and a mechanical resonance. Double-cantilever beam model with a tip mass such as a permanent magnet was excited by using the electromagnetic force. Then, double-cantilever beam model performs resonance, and a resonance energy produces rotational torque. This motor has the characteristic of the low-speed and high output torque, and the structure is considerably simple. Thus, a simple structure of this motor allows manufacturing costs to be inexpensive.

In experiment, the rotational properties of double-cantilever beam model composed by two translational springs were examined firstly. Next, the motor with double-cantilever beam of multiple was fabricated, and the influence of each parameter on torque and efficiency property was considered.

\section{Structure of Magnetic Plane Motor}

A new type of a magnetic plane motor coupled mechanical vibration with electromagnetic force was fabricated and tested. This magnetic plane motor realizes a rotational torque of one direction using a frictional force and an inertial force produced in a mechanical resonance. Figure 1 shows a schematic diagram of this magnetic plane motor, which is capable of rotation within plane. The magnetic plane motor consists of double-cantilever beam model, an electrical coil, a permanent magnet A to hold double-cantilever beam model, an iron circular plate and a bearing. Permanent magnet $\mathrm{A}$ has an outer diameter of $2 \mathrm{~mm}$, and a thickness of $2 \mathrm{~mm}$. Permanent magnet $\mathrm{A}$ is a $\mathrm{NdFeB}$ magnet and is magnetized in the axial direction.

Figure 2 demonstrates double-cantilever beam model composed by two translational springs, a permanent magnet B, and a thin plastic sheet. Permanent magnet B has a length of $3 \mathrm{~mm}$, a width of $3 \mathrm{~mm}$ and a thickness of $2 \mathrm{~mm}$. Permanent magnet B is the NdFeB magnet and is magnetized in the length direction. The surface magnetic flux density measured using a tesla meter is $265 \mathrm{mT}$ for permanent magnet $\mathrm{A}$, and $370 \mathrm{mT}$ for permanent magnet B. The two identical translational springs are stainless steel compression coil type and have an outer diameter of $0.96 \mathrm{~mm}$, a free length of $2.1 \mathrm{~mm}$ and a spring constant in the longitudinal direction $\mathrm{k}=1425$ $\mathrm{N} / \mathrm{m}$. The mass-spring vibration model was created combining double-cantilever model and the permanent magnet $\mathrm{B}$ as shown in Figure 2. This plane motor converts the mechanical resonance energy stimulated by the AC electrical power source into rotational power. We chose the dimensions as a width of $6.5 \mathrm{~mm}$, and a thickness of $1.5 \mathrm{~mm}$ so that the thin plastic sheet was flexible at up and down direction, and rigidity became higher at right and left direction as shown in Figure 2. Double-cantilever model was attached to a bearing through this plastic sheet. This magnetic plane motor has a diameter of $30 \mathrm{~mm}$, a height of $3 \mathrm{~mm}$ and total mass of $9.4 \mathrm{~g}$. The permanent magnet B is supported by two translational springs with angle $\alpha$. At thus attached permanent magnet, double-cantilever model vibrates in diagonal direction $f_{H}$ or $f_{L}$ by Fleming's left hand rule when we apply an alternating electrical current into the coil. Two vibration modes can change by changing resonance frequency of double-cantilever model due to double-cantilever model. By the choice of these vibration modes, the rotatory direction of the magnetic plane motor can control.

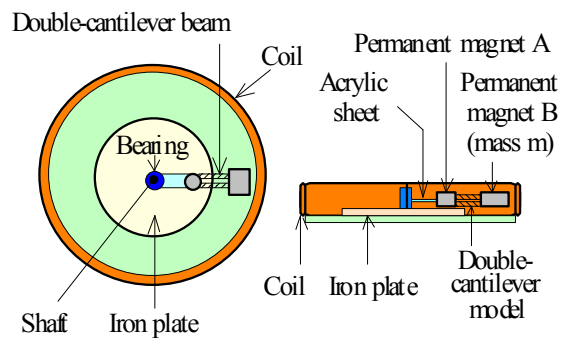

(a)
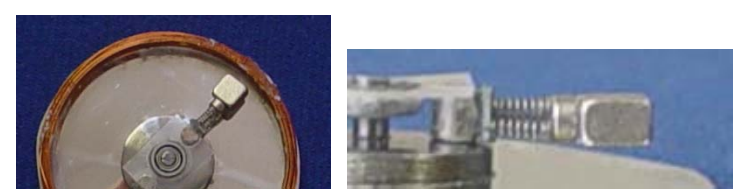

(b)

Figure 1. Structure of magnetic plane motor. (a) Outline of magnetic plane motor; (b) Photograph of magnetic plane motor. 

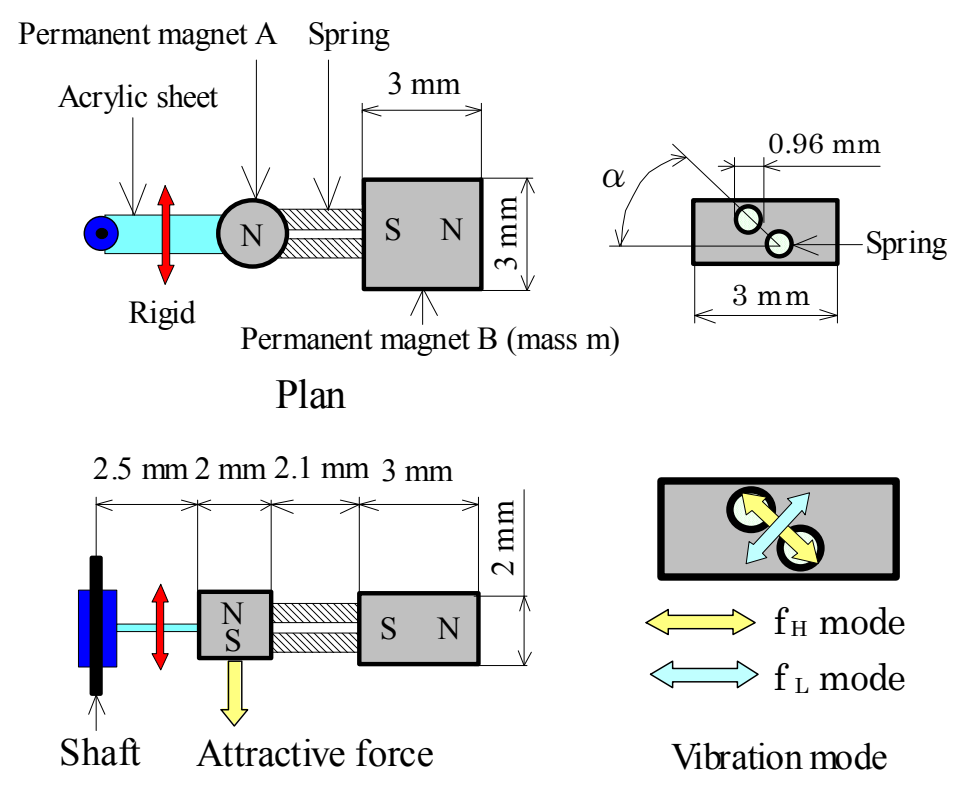

Front view

Figure 2. Detail of vibration model.

\section{Principle of Rotation}

This magnetic plane motor can rotate by using changing of an inertia force and a bending moment of doublecantilever model when two springs attached diagonally vibrate. The vibration model can vibrate with two modes of $f_{H}$ mode and the $f_{L}$ mode. The rotatory direction of the motor is able to change by the changing of the vibration mode. We think that the vibration model vibrates with $\mathrm{f}_{\mathrm{H}}$ mode as shown in Figure 2. The permanent magnet $\mathrm{A}$ is held by the attractive force on the iron plate. The principle of rotation is as follows:

1) The vibrating mass $m$ produces the sharing force $F$ and the bending moment $M$ at the permanent magnet $A$. These sharing force and bending moment change periodically during one period of the vibration. As shown in Figure 3(a), the holding force of the permanent magnet $\mathrm{A}$ is degreased due to inertia force of a vibrating mass $\mathrm{m}$ when the mass $\mathrm{m}$ vibrates in the direction of coordinate $\mathrm{z}$. The magnetic plane motor is able to slide when the bending moment produced by the vibrating mass $\mathrm{m}$ is bigger than the moment by the frictional force between the permanent magnet $\mathrm{A}$ and the iron plate.

2) On the other hand, the holding force of the permanent magnet $A$ is increased due to effect of the inertia force of the vibrating mass $m$ when the mass $m$ moves in the opposite direction of coordinate $z$. In this case, the moment by the frictional force between the permanent magnet A and the plate of the iron becomes quite big compare with the bending moment produced by the vibrating mass $\mathrm{m}$. Therefore, the magnetic plane motor is not able to rotate.

3) The frictional force between the permanent magnet $\mathrm{A}$ and the plate of the iron alternately changes during one period of the vibration as mentioned above. As a result, the magnetic plane motor is able to rotate only in the one direction.

\section{Rotational Properties of Magnetic Plane Motor}

An experimental test was conducted using an apparatus shown in Figure 4. The resonance frequency of $\mathrm{f}_{\mathrm{H}}$ mode measured by using an experimental apparatus was $167 \mathrm{~Hz}$, and that of $\mathrm{f}_{\mathrm{L}}$ mode was $100 \mathrm{~Hz}$. The coil with 20 turns of $0.2 \mathrm{~mm}$ diameter copper wire was used. The electrical resistance of the coil is $1.7 \Omega$, the air gap between the coil and the permanent magnet $\mathrm{B}$ is $1.5 \mathrm{~mm}$.

Figure 5 shows the relationship between the input current into the coil and rotational speed of $\mathrm{f}_{\mathrm{H}}$ mode for the vibration model with angle $\alpha$ when the attractive force $\mathrm{F}$ of the permanent magnet A was changed to $0.39 \mathrm{~N}, 0.63$ $\mathrm{N}, 1.04 \mathrm{~N}$ and $1.49 \mathrm{~N}$. The attractive force was changed by inserting a thin acrylic seat between the iron plate 


\section{Rotatable}

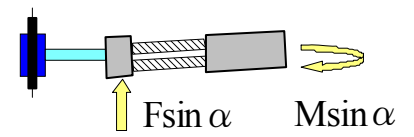

$\left.\mathrm{M}\right|_{0} ^{\mathrm{Z}}$

Magnet A

Non rotatable

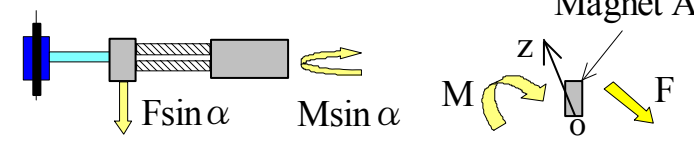

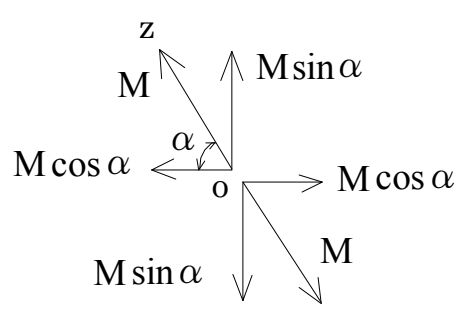

Attractive force

Force and moment on permanent magnet $\mathrm{A}$

Figure 3. Change of sharing force and bending moment.

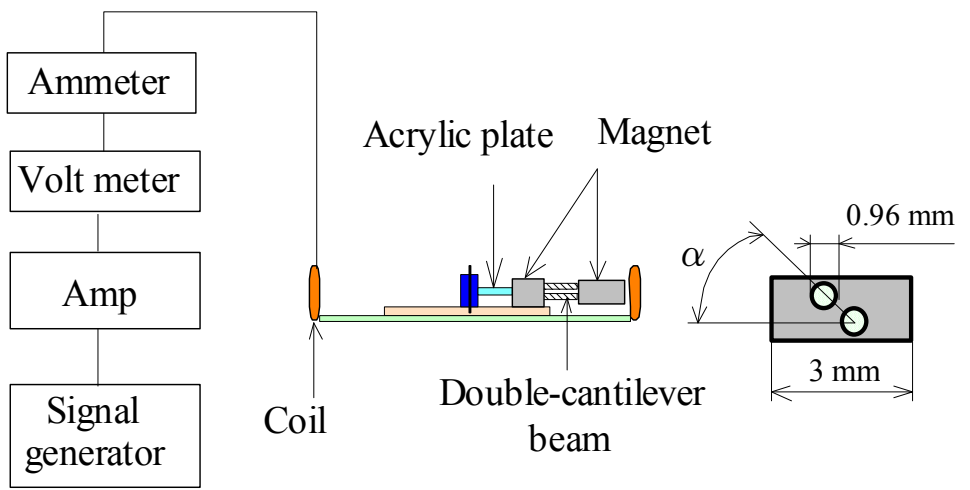

Figure 4. Experimental apparatus.

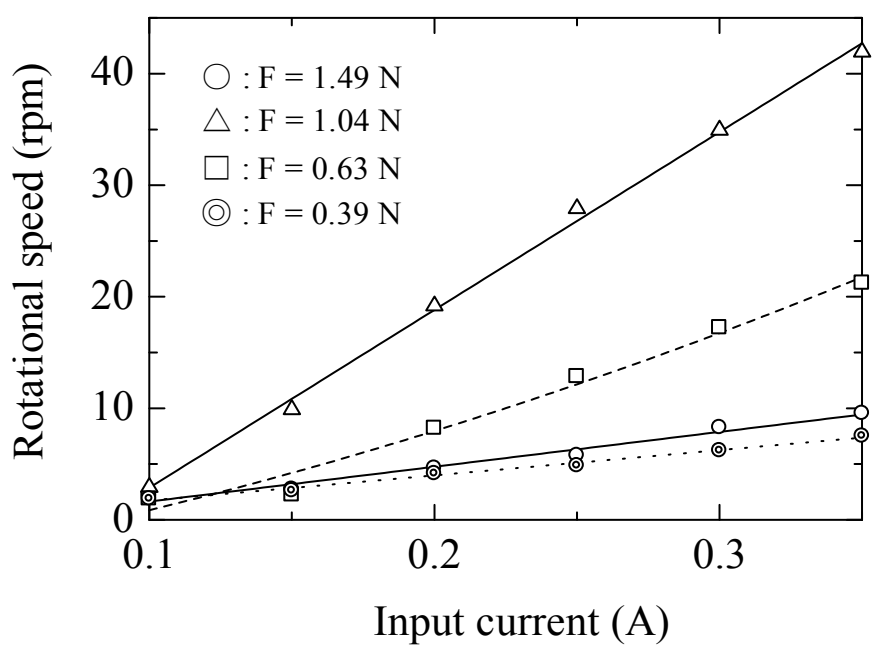

Figure 5. Relationship between input current and rotational speed $\left(\mathrm{f}_{\mathrm{H}}\right.$ mode). 
and the permanent magnet $\mathrm{A}$. The attractive force was measured by using a force gage. At this time, the coefficient of friction measured by the experiment is $\mu=0.2$.

On the other hand, Figure 6 shows the result for the case of $f_{L}$ mode. In both modes, the rotational speed of the plane motor increases in proportion by increase of the input current. The appropriate force of the permanent magnet A maximizing the rotational speed exists for both mode of $f_{H}$ and $f_{L}$.

Figure 7 shows the relationship between angle $\alpha$ of double-cantilever beam composed by using two translational springs and rotational speed of $\mathrm{f}_{\mathrm{H}}$ mode when the input current was changed. In this case, an optimal attached angle of the springs indicating the maximum value of the rotational speed exists. The following results are provided by arrangement the measured data by the experiment.

1) The optimal attractive force of the permanent magnet A maximizing the rotational speed exists for $f_{H}$ mode and $\mathrm{f}_{\mathrm{L}}$ mode.

2) The rotational speed increases approximately linearly when the input current increases.

3) When the angle $\alpha$ of two translational springs was set to 60 degrees, the rotational speed of the magnetic plane motor demonstrates maximum value. Based on these results, in the following, the angle $\alpha$ measures a torque property of the magnetic plane motor as 60 degrees.

Figure 8 shows the outline of the output torque measurement. The output torque was measured by using the frictional force due to locating the one permanent magnet $\mathrm{C}$ in the other side of the vibration model. The used permanent magnet is the cylindrical $\mathrm{NdFeB}$ and is magnetized in the axial direction. This is $6 \mathrm{~mm}$ in diameter, and height is $3 \mathrm{~mm}$. This permanent magnet was set on the iron plate. When the plane motor rotates, the fric-

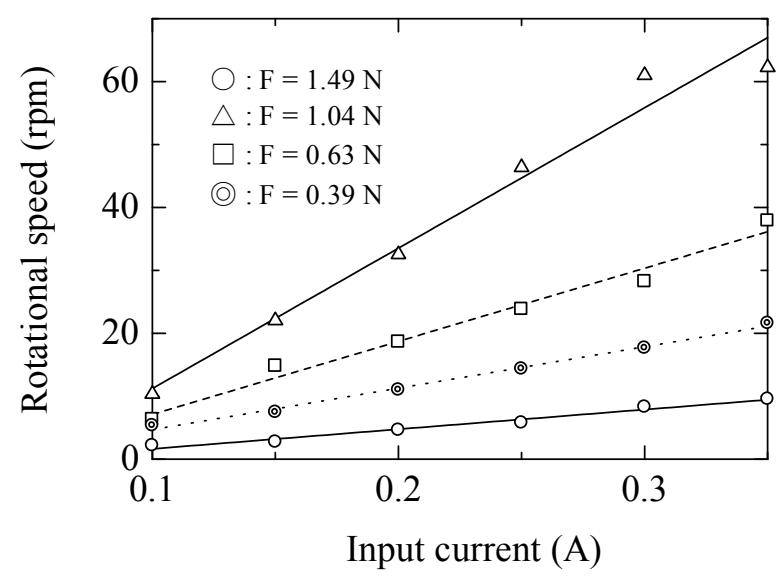

Figure 6. Relationship between input current and rotational speed $\left(f_{\mathrm{L}}\right.$ mode).

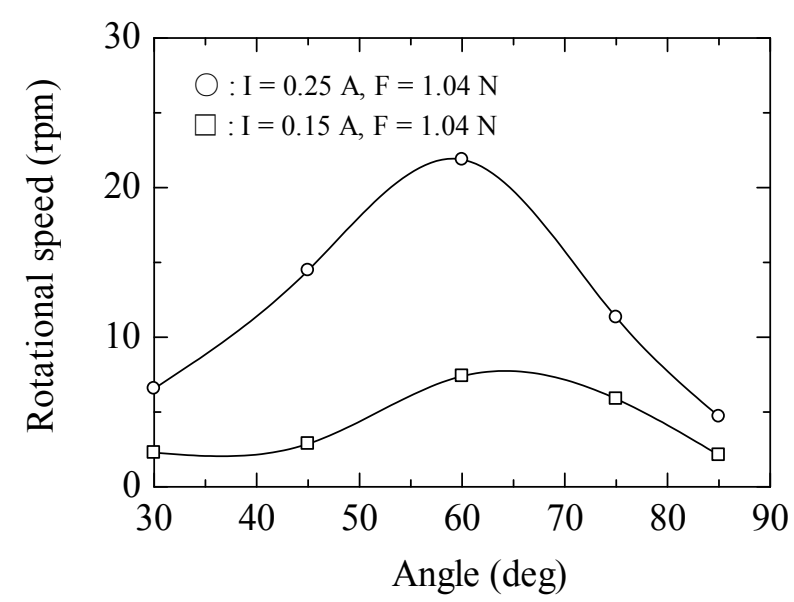

Figure 7. Relationship between angle and rotational speed $\left(\mathrm{f}_{\mathrm{H}}\right.$ mode). 
tional force $\mathrm{F}^{\prime}$ acts between the iron plate and the permanent magnet $\mathrm{C}$. Accordingly, the load torque acts on the motor during the plane motor is rotating. The attractive force between the iron plate and the permanent magnet $\mathrm{C}$ was set to $\mathrm{F}=0.63 \mathrm{~N}$. The coefficient of friction is $\mu=0.2$. The output torque $\mathrm{T}$ is expressed as $\mathrm{T}=\mathrm{F}^{\prime}(\mu \mathrm{F}) \times \mathrm{R}$. $\mathrm{F}^{\prime}$ is the frictional force between the permanent magnet $\mathrm{C}$ and the iron plate, and $\mathrm{R}$ is radius of rotation. In measurement, we changed the load torque by changing radius $\mathrm{R}$ as shown in Figure 7 . The coil with 48 turns of $0.2 \mathrm{~mm}$ diameter copper wire was used. The electrical resistance was $3 \Omega$, the air gap between the coil and the permanent magnet $B$ was set to $1.5 \mathrm{~mm}$.

Figure 9 and Figure 10 show for two double-cantilever models relationship between the output torque and

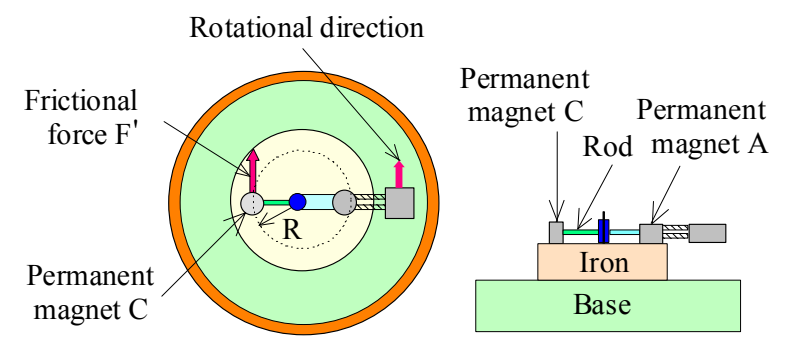

Figure 8. Outline of the torque measurement.

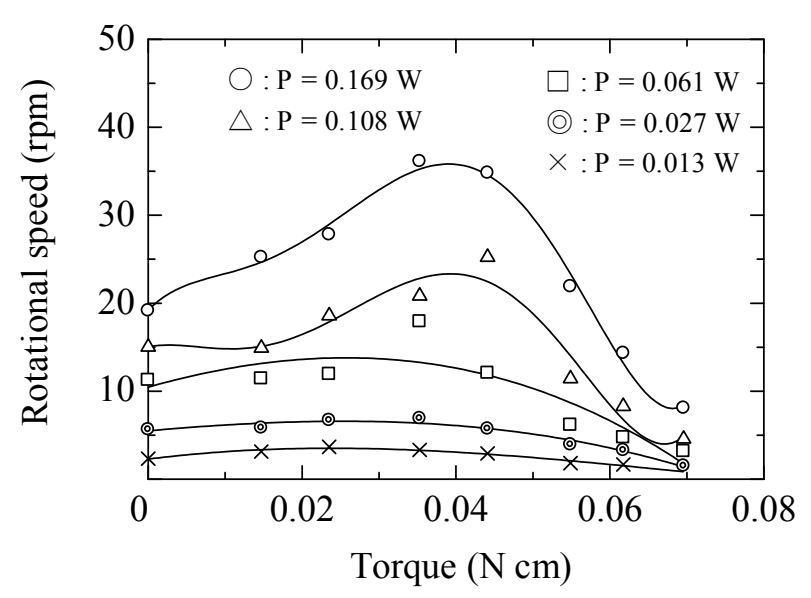

Figure 9. Relationship between output torque and rotational speed $\left(f_{H}\right.$ mode $)$.

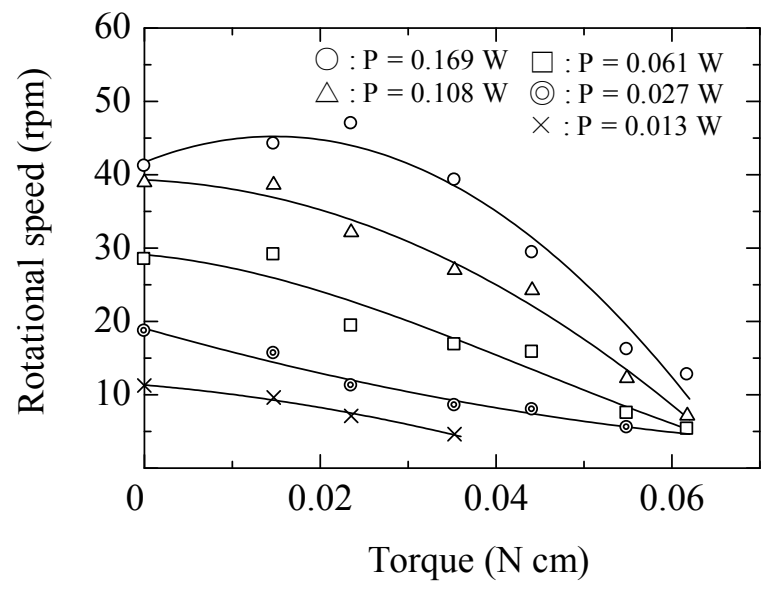

Figure 10. Relationship between output torque and rotational speed $\left(f_{L}\right.$ mode $)$. 
rotational speed by changing the input power $P$ into the coil. In the case of $f_{H}$ mode, it is observed that this plane motor produces the high output torque of $0.07 \mathrm{~N} \cdot \mathrm{cm}(7.1 \mathrm{gfcm})$ when the rotational speed was $8.1 \mathrm{rpm}$.

Figure 11 and Figure 12 show for two double-cantilever models relationship between the output torque and the efficiency when input power P into the coil was changed. One mass-spring model using double-cantilever model produces the high torque, but the maximum efficiency was $1.1 \%$ at $\mathrm{f}_{\mathrm{H}}$ mode, and that of $\mathrm{f}_{\mathrm{L}}$ mode was $1.4 \%$.

Next, the magnetic plane motor with two double-cantilever models was constructed as shown in Figure 13. In this case, the magnetic plane motor has a diameter of $30 \mathrm{~mm}$, a height of $3 \mathrm{~mm}$ and total mass of $10.4 \mathrm{~g}$. A measurement of rotational speed of the plane motor with two double-cantilever models was conducted. As the output torque, two permanent magnets $\mathrm{C}$ were used. Figure 14 shows photograph of the magnetic plane motor with two double-cantilever models.

The solid line in Figure 15 shows relationship between input power P into the coil and rotational speed. In this case, the output torque $\mathrm{T}$ was set to $0.0686 \mathrm{Ncm}(7 \mathrm{gfcm})$. On the other hand, the broken line shows case of the plane motor with double-cantilever model when the output torque $\mathrm{T}$ was set $0.0343 \mathrm{Ncm}(3.5 \mathrm{gfcm})$. The output torque of the magnetic plane motor with two double-cantilever models demonstrates approximately two times of that with double-cantilever model because both motors rotate at the same rotational speed. This magnetic plane motor has the space that can set six vibration models. This plane motor will generate the maximum output torque of approximately $0.412 \mathrm{Ncm}$ (42 gfcm).

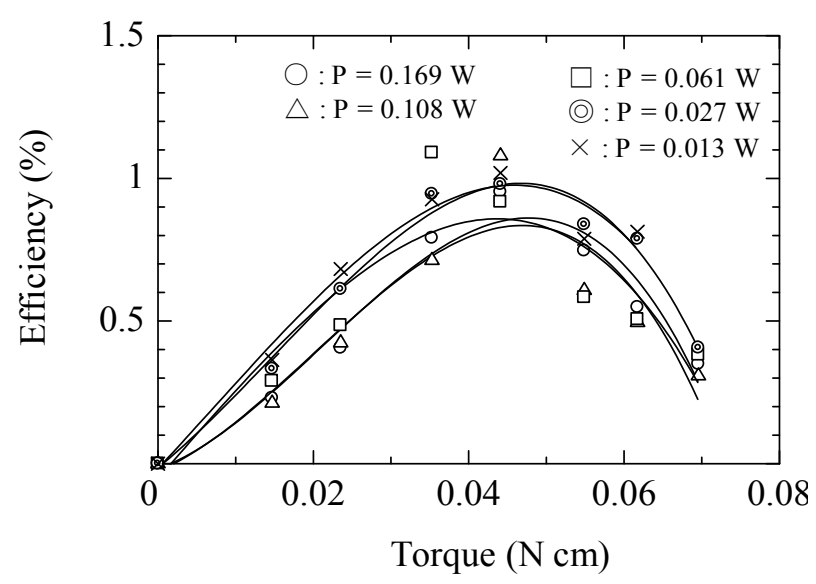

Figure 11. Relationship between output torque and efficiency ( $f_{\mathrm{H}}$ mode).

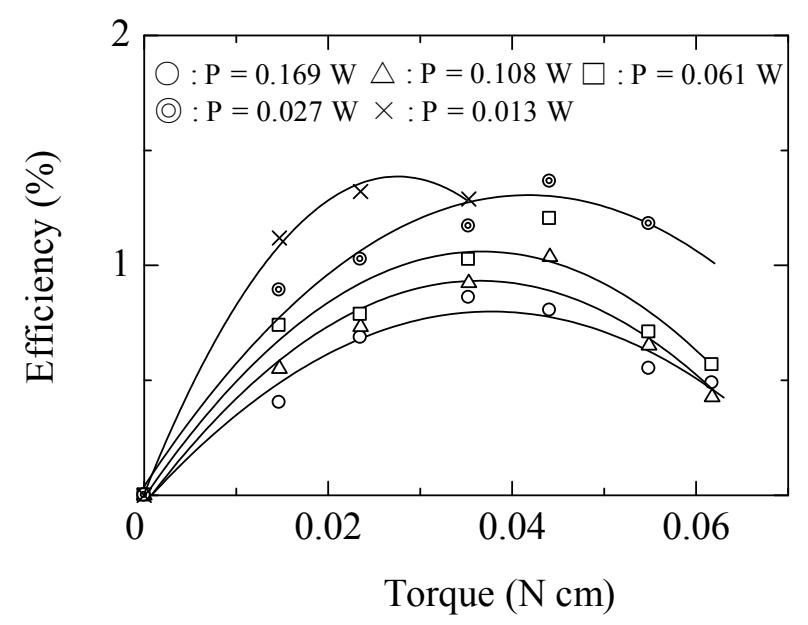

Figure 12. Relationship between output torque and efficiency ( $f_{\mathrm{L}}$ mode). 


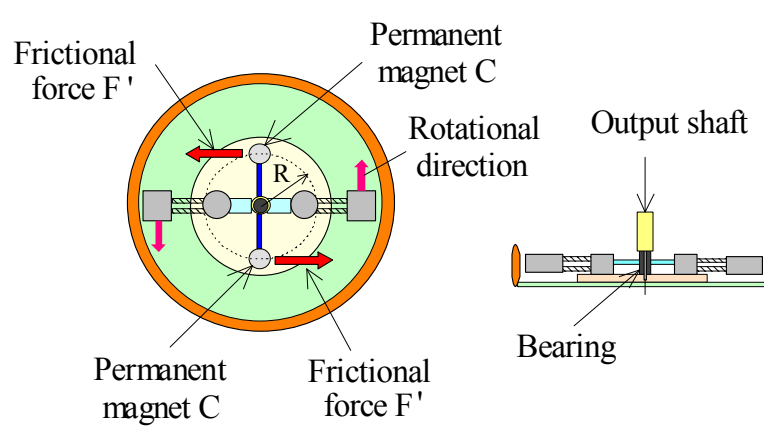

Figure 13. Plane motor with two double-cantilever models.

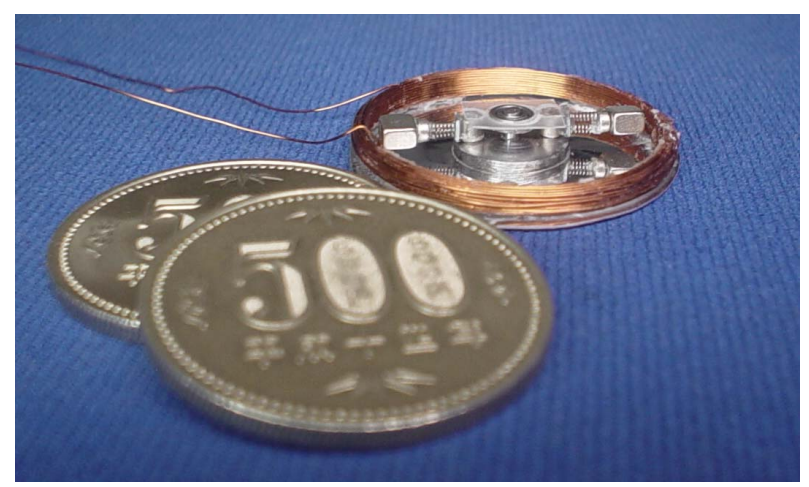

Figure 14. Photograph of magnetic plane motor.

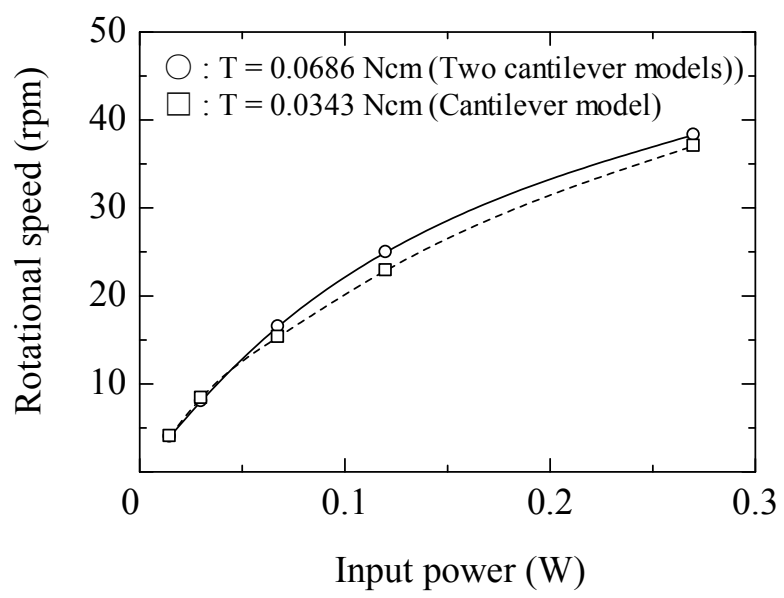

Figure 15. Relationship between input power and rotational speed $\left(f_{H}\right.$ mode $)$.

\section{Conclusions}

A new type of a magnetic plane motor which combined an electromagnetic force, and a mechanical resonance was proposed and tested. Basic characteristics of a prototype for the plane motor with double-cantilever model, such as rotational speed, an output torque and efficiency were determined experimentally. In the case of $\mathrm{f}_{\mathrm{H}}$ mode, the magnetic plane motor produces the high output torque of $0.07 \mathrm{Ncm}$. At this time, the maximum efficiency was $1.1 \%$. We think that this plane motor can generate the maximum output torque of approximately $0.412 \mathrm{Ncm}$. Also, it is expected that the maximum efficiency becomes $6.6 \%$ with $\mathrm{f}_{\mathrm{H}}$ mode and $8.4 \%$ with $\mathrm{f}_{\mathrm{L}}$ mode, respectively.

By the improvement of the magnetic circuit to oscillate the vibration body, we are going to achieve improve- 
ment of the output torque and efficiency in future. Future research will be directed toward these goals.

\section{References}

[1] Yamamoto, A., Nishijima, T. and Higuchi, T. (2005) High-Power Double-Sided Drive Type Electrostatic Motor with Stacked-Film Structure. The Japan Society for Precision Engineering, 71, 1245-1249.

[2] Kurosawa, M. (2003) Surface Acoustic Wave Linear Motor. Advanced Robotics, 21, 736-739.

[3] Niino, T., Higuchi, T. and Egawa, T. (1997) AC Dual Excitation Multiphase Electrostatic Drive. Advanced Robotics, 15, 1147-1155.

[4] Fan, L.S., Tai, Y.C. and Muller, R.S. (1988) IC-Processed Electrostatic Micro-Motors. Proceedings of IEEE International Electron Devices Meeting, San Francisco, 11 December 1988, 666-669.

[5] Jacobsen, S.C., Price, R.H. and Wood, J.E. (1989) The Wobble Motor: An Electrostatic, Planetary-Armature, Miroactuator. Proceedings of IEEE Micro Electro Mechanical Systems Workshop '89, Solt Lake City, 20 February 1989, 17-24.

[6] Yokota, S., Kuwajima, S., Kondo, Y. and Edamura, K. (2004) Realization of a Higher Integrated Multi-Layered DP-RE Type ECF Micro-Motor. Transactions of Japan Society of Mechanical Engineers, 70, 1463-1469. http://dx.doi.org/10.1299/kikaic.70.1463

[7] Sharma, S.V., Nayak, M.M. and Dinesh, N.S. (2008) Shape Memory Alloy Based Motor. Sadhana, 33, 699-712.

[8] Reynaerts, D. and Brussel, H.V. (1998) Design Aspects of Shape Memory Actuators. Mechatronics, 8, 635-656. http://dx.doi.org/10.1016/S0957-4158(98)00023-3

[9] Vranish, J.M., Naik, D.P., Restorff, J.B. and Teter, J.P. (1991) Magnetostrictive Direct Drive Rotary Motor Development. IEEE Transaction on Magnetics, 27, 5355-5357. http://dx.doi.org/10.1109/20.278837

[10] Claeyssen, F., Lhermet, N., Letty, R. and Bouchilloux, P. (1996) Design and Construction of a Resonant Magnetostrictive Motor. IEEE Transaction on Magnetics, 32, 4749-4751. http://dx.doi.org/10.1109/20.539139

[11] Pack, I.S., Oh, O.K., Pack, Y.W. and Wereley, N.M. (2013) A Nobel Concept and Proof of Magnetostrictive Motor. IEEE Transaction on Magnetics, 49, 3379-3382. http://dx.doi.org/10.1109/TMAG.2013.2243132

[12] Maruno, T., Honda, T. and Yamasaki, J. (2000) Considerations on Increase in the Torque of an Electromagnetic Friction-Drive Micro-Motor. Transaction IEE of Japan, 120-A, 289-294. 
Scientific Research Publishing (SCIRP) is one of the largest Open Access journal publishers. It is currently publishing more than 200 open access, online, peer-reviewed journals covering a wide range of academic disciplines. SCIRP serves the worldwide academic communities and contributes to the progress and application of science with its publication.

Other selected journals from SCIRP are listed as below. Submit your manuscript to us via either submit@scirp.org or Online Submission Portal.
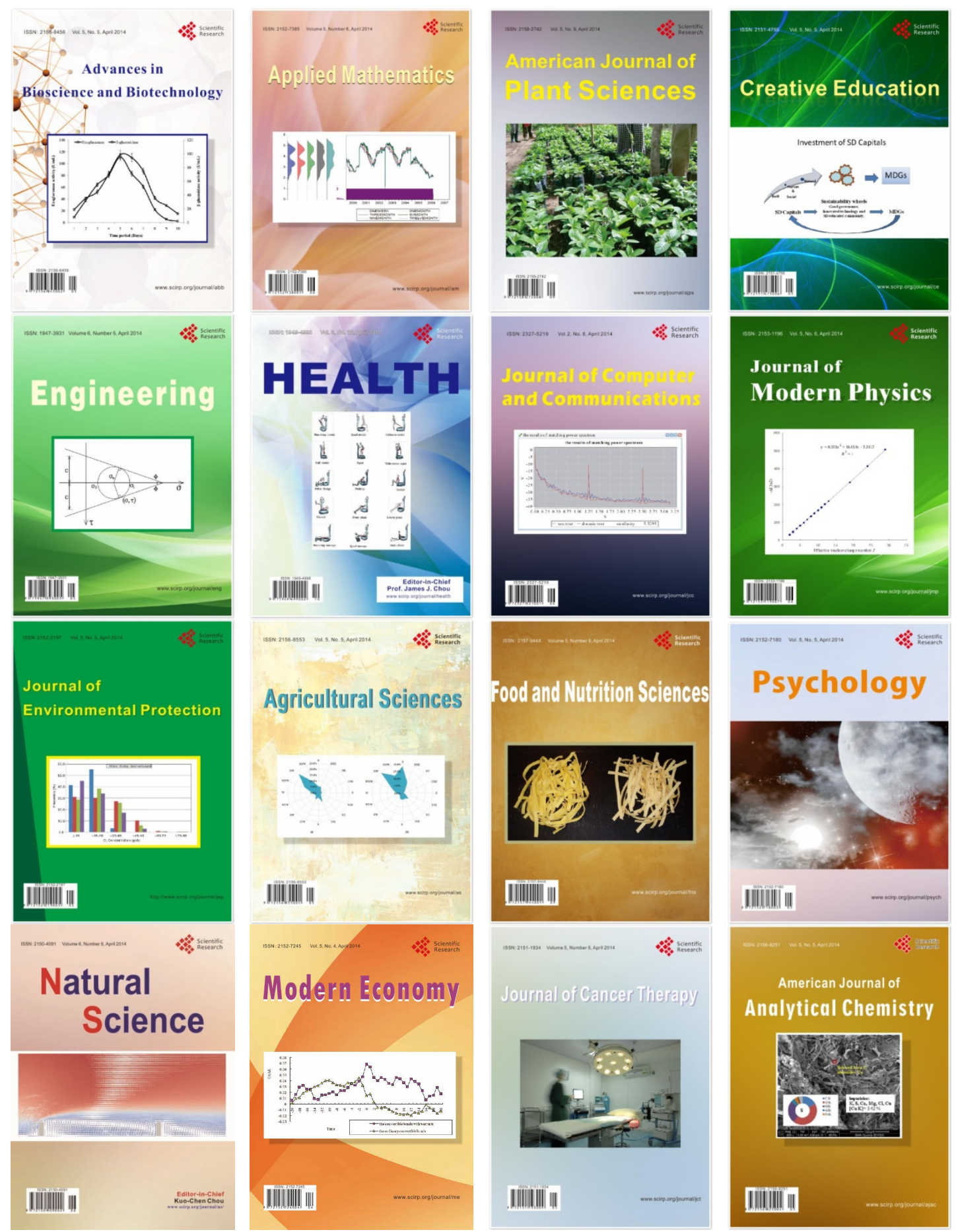